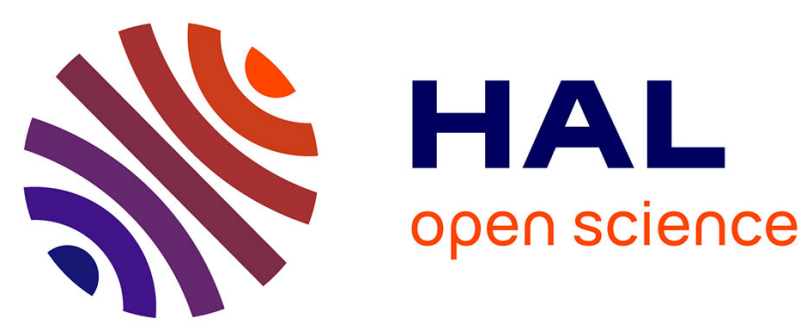

\title{
Design and fabrication of photonic crystals in epitaxy-free silicon for ultrathin solar cells
}

Xianqin Meng, Valerie Depauw, Guillaume Gomard, Ounsi El Daif, Christos Trompoukis, Emmanuel Drouard, Alain Fave, Frederic Dross, Ivan Gordon, Christian Seassal

\section{To cite this version:}

Xianqin Meng, Valerie Depauw, Guillaume Gomard, Ounsi El Daif, Christos Trompoukis, et al.. Design and fabrication of photonic crystals in epitaxy-free silicon for ultrathin solar cells. Asia Communications and Photonics Conference and Exhibition, Nov 2011, Shanghai, China. pp.831207-831207-7, $10.1117 / 12.904383$. hal-00666247

\section{HAL Id: hal-00666247 https://hal.science/hal-00666247}

Submitted on 3 Feb 2012

HAL is a multi-disciplinary open access archive for the deposit and dissemination of scientific research documents, whether they are published or not. The documents may come from teaching and research institutions in France or abroad, or from public or private research centers.
L'archive ouverte pluridisciplinaire HAL, est destinée au dépôt et à la diffusion de documents scientifiques de niveau recherche, publiés ou non, émanant des établissements d'enseignement et de recherche français ou étrangers, des laboratoires publics ou privés. 


\title{
Design and fabrication of photonic crystals in epitaxial free silicon for ultrathin solar cells
}

\author{
Xianqin Meng ${ }^{*}{ }^{1,2}$, Valerie Depauw ${ }^{3}$, Guillaume Gomard ${ }^{* 1,2}$, Ounsi El Daif ${ }^{3}$, Christos \\ Trompoukis ${ }^{3}$, Emmanuel Drouard ${ }^{* 1}$, Alain Fave ${ }^{* 2}$, Frederic Dross ${ }^{3}$, Ivan Gordon ${ }^{3}$ and \\ Christian Seassal ${ }^{* 1}$ \\ * Université de Lyon, Institut des Nanotechnologies de Lyon (INL) UMR 5270 CNRS- INSA-ECL-UCBL \\ ${ }^{1}$ Ecole Centrale de Lyon, 36 avenue Guy de Collongue, 69134, Ecully Cedex, FRANCE \\ ${ }^{2}$ INSA de Lyon, Bat. Blaise Pascal, 7 avenue Capelle, 69621, Villeurbanne, FRANCE \\ ${ }^{3}$ IMEC vzw, Kapeldreef 75, 3001 Leuven, BELGIUM
}

\begin{abstract}
In this paper, we present the integration of an absorbing photonic crystal within a thin film photovoltaic solar cell. Optical simulations performed on a complete solar cell revealed that patterning the epitaxial crystalline silicon active layer as a $1 \mathrm{D}$ and $2 \mathrm{D}$ photonic crystal enabled to increase its integrated absorption by $37 \%$ abs and $68 \%$ abs between $300 \mathrm{~nm}$ and $1100 \mathrm{~nm}$, compared to a similar but unpatterned stack. In order to fabricate such promising cells, a specific fabrication processes based on holographic lithography, inductively coupled plasma etching and reactive ion etching has been developed and implemented to obtain ultrathin patterned solar cells.
\end{abstract}

Keywords: Photonic crystals; Epitaxial crystalline silicon; Thin-film devices and applications; Photovoltaics; Holographic lithography

\section{Introduction}

In order to overcome the limitations of classical thin film silicon solar cells, integrating planar Photonic Crystals (PCs) structures ${ }^{[1-3]}$ has appeared as an attractive solution. The PCs have been considered to create either back reflectors ${ }^{[4]}$ or selective filters for tandem solar cells ${ }^{[5]}$. Meanwhile, thin film crystalline-silicon (c-Si) solar cells are one of the promising candidates for low cost photovoltaic applications thanks to commercially compatible mass production processes ${ }^{[6]}$. Considering both fabrication costs and bulk recombination issues, the thickness of c-Si layer should be limited as much as possible. Increasing its absorption through PCs light trapping techniques is then essential to achieve reasonable conversion efficiencies on such devices. More precisely, to enable efficient current generation, light trapping schemes are essential to capture the red and near-infrared part of the solar spectrum ${ }^{[7,8]}$. We recently proposed to pattern the absorbing layer itself as a planar PC. This approach constitutes an efficient light trapping technique and can lead to a substantial increase of the solar light absorption over a wide spectral range ${ }^{[3,9,10,11]}$. Out of this concept, and considering c-Si based structures, we proposed to control light capture and absorption using planar PCs Bloch modes that stand over the light-line. Such nanopatterns allow thin c-Si absorbing layers (with thicknesses of around $1000 \mathrm{~nm}$ ), i.e. much lower than the diffusion length of the minority carriers. The absorption increase related to light trapping is then expected to lead to short-circuit current densities exceeding those similar unpatterned cells.

In order to generate such PC patterns in a compliance with industrial requirements, relevant techniques then include nano-imprint ${ }^{[12]}$ and holographic lithography; they are essential to develop a high throughput process compatible with large surfaces. Additionally, holographic lithography is a maskless process, particularly wellsuited to the fabrication of periodic patterns like PCs ${ }^{[13,14,15,16]}$. Its parameters have been carefully adjusted and controlled from our previous investigation based on the desired stack and pattern ${ }^{[17]}$. 
In this paper, we report on a way of patterning the epitaxial free $\mathrm{c}-\mathrm{Si}^{[6]}$ as a $1 \mathrm{D}$ and $2 \mathrm{D}$ PC. The global design of the ultra-thin film solar cell, which has been optimized optically by simulation, is introduced in section 2 . Its optical properties as well as the parameters of the PC membrane which maximize the absorption in the active layer are also discussed in this section, which defines the objectives to attain for further experimental development. This last point is developed in section 3. After presenting the general fabrication process of our patterned cells, we finally generate the targeted pattern by combining holographic lithography with an ICP and RIE steps.

\section{Optical design of 1D and 2D PC c-Si thin film solar cells}

The basic solar cell structure consists, from the back to the front, of a glass substrate, a silver (Ag) layer acts as a reflector and metallic conductor, a p-doped c-Si layer, an real absorbing c-Si layer, a n-doped a-Si:H and a top transparent conductive oxide (TCO) layer deposited at the end of the pattering process to be an anti-reflector layer. As described in Fig.1, the top layers are patterned as planar PCs. The finite-difference time-domain (FDTD) approach numerically solves the differential form of Maxwell's equations, so that complex device design can be molded and optimized device designs can be determined ${ }^{[18]}$. To investigate the wave propagation in the patterned c-Si membrane and the thin film c-Si solar cells, the AM1.5G solar spectrum intensity distribution was taken into account over the $300-1100 \mathrm{~nm}$ spectral range; these bounds roughly and respectively corresponds to the lower limit of the solar spectrum and the c-Si gap. The boundary conditions for $\mathrm{x}$ and $\mathrm{y}$ directions are periodic and Perfectly Matched Layers (PML) for 1D PCs. For the 2D PC simulation, the x, y directions are set as Periodic, and $\mathrm{z}$ is PML.

The first test is based on a single $1 \mu \mathrm{m} \mathrm{c-Si} \mathrm{layer,} \mathrm{which} \mathrm{is} \mathrm{patterned} \mathrm{by} \mathrm{1D} \mathrm{PC} \mathrm{and} \mathrm{2D} \mathrm{PC} \mathrm{with} \mathrm{the} \mathrm{same} \mathrm{period,}$ air filling faction (ff) and etching depth, in order to compare the absorption spectra with the planar c-Si layer, as shown on Fig.1. It indicates that the absorption spectra in the patterned 2D and 1D PC layers is respectively 57\% and $50 \%$ under normal incident, which is higher than $31 \%$ from the planar c-Si layer. The main is achieved over $0.61 \mu \mathrm{m}$, which corresponds to the lattice parameter of the PCs. Moreover, under normal incidence, the absorption efficiency of 2D PC layer does not depend on the polarization of the incident light. In the planar c-Si layer, from about $450 \mathrm{~nm}$ to $1100 \mathrm{~nm}$, the clearly visible absorption resonances correspond to Fabry-Perot modes thanks to the large index contrast between air and c-Si layer. If these resonances can lead to a complete absorption of the incident light, the spectral density of modes is limited by the low thickness of the layer, leading to low integrated absorption on the whole spectral range. Moreover, the large index contrast leading to a high reflection is also responsible for the low absorption $(\sim 50 \%)$. Then, the envisaged roles of the PC are twofold: to reduce the reflection at short wavelengths, and to increase the spectral density of modes at large wavelengths. 


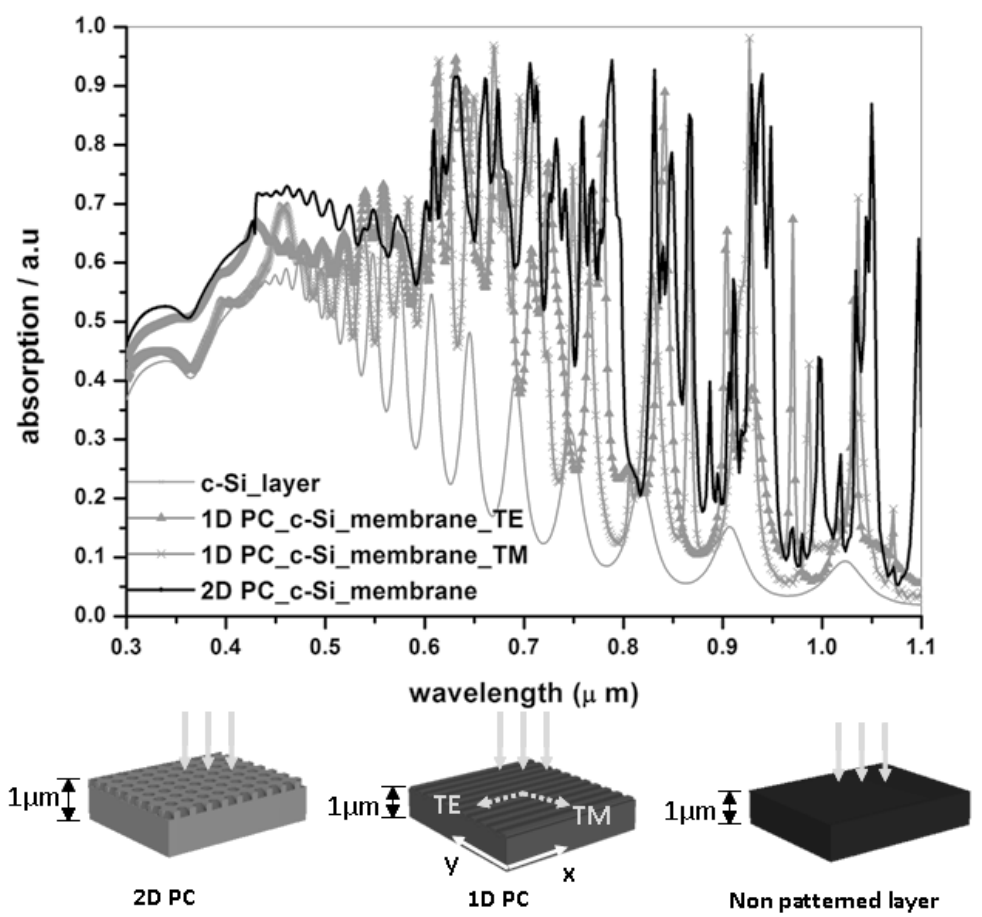

Fig.1. Absorption spectra in the patterned 2D and 1D PC c-Si layer with the same period, ff and etching depth (period $=0.61 \mu \mathrm{m}, \mathrm{ff}=65 \%$ and etching depth $=0.14 \mu \mathrm{m})$, compared to the planar layer

Based on the investigation of the single c-Si layer, the now considers a complete solar stack with a planar PC. It includes, from back to front, a $100 \mathrm{~nm}$ thick silver $(\mathrm{Ag})$ layer, then the p-i-n junction, and an ITO layer. The considered values of lattice parameter (L) and ff, defined by $\mathrm{D} / \mathrm{L}$, as well as the etching depth can be achieved using the selected technological processes, as shown on Fig.2. More precisely, the configurations of the patterned cell were investigated by scanning simultaneously $L$ between $0.3 \mu \mathrm{m}$ and $0.6 \mu \mathrm{m}$ per $0.01 \mu \mathrm{m}$, and ff between 0.3 and 0.7 per 0.05 . The range of the etching depth has been changed from $0.08 \mu \mathrm{m}$ to $0.3 \mu \mathrm{m}$ per 0.02 $\mu \mathrm{m}$, which were scanned over such wide ranges so as to maximize the absorption in the "photonized" c-Si layer.

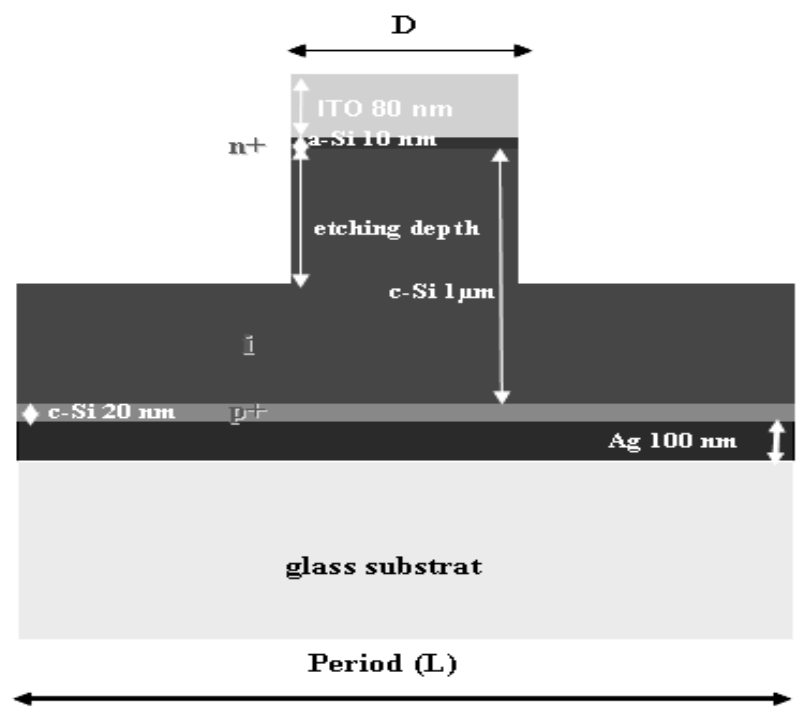

Fig.2. Schematic view of a "photonized" solar cell with a 1D pattern. Photogenerated carriers originating from the $\mathrm{c}-\mathrm{Si}$ active layer are collected through the ITO and the Ag layer 
The absorption spectra of the whole stack and c-Si layer, which are displayed on Fig.3, indicate the patterned stacks have higher absorption than the reference stack both in the stack and in the sole c-Si layer. Moreover, a maximal value for the integrated absorption of the whole $1 \mathrm{D}$ patterned cell is about $71 \%$ over for $\mathrm{L}=0.61 \mu \mathrm{m}$, $\mathrm{D} / \mathrm{L}=65 \%$ and etching depth $=0.14 \mu \mathrm{m}$. Looking for the useful part of this integrated absorption, namely the one in the sole active layer, we found that optimized parameters of 1D patterned stack could be determined yielding to $46 \%$, a theoretical improvement of $37 \%$ of the absolute absorption efficiency in the sole c-Si, compared to $33.7 \%$ of unpatterned configuration in normal incidence. The important increase of absorption efficiency in the c-Si layer is expected to give rise to a subsequent gain of the conversion efficiency of such a 1 $\mu \mathrm{m}$ thick c-Si solar cell.

As evidenced in our former work for a different configuration on a-Si: $\mathrm{H}^{[11]}$, the absorption efficiency of thin film solar cells integrating 2D PC should lead to higher gains than their 1D counterpart. As an example, by choosing the same lattice parameter, surface filling fraction and etching depth as in the case of the 1D PC, the absorption in the sole c-Si obtained within the 2D PC patterned stack is $56.5 \%$, which is higher than the one from the 1D PC stack and the unpatterned stack to $23 \%$ and $68 \%$, as well as independent of the polarization.
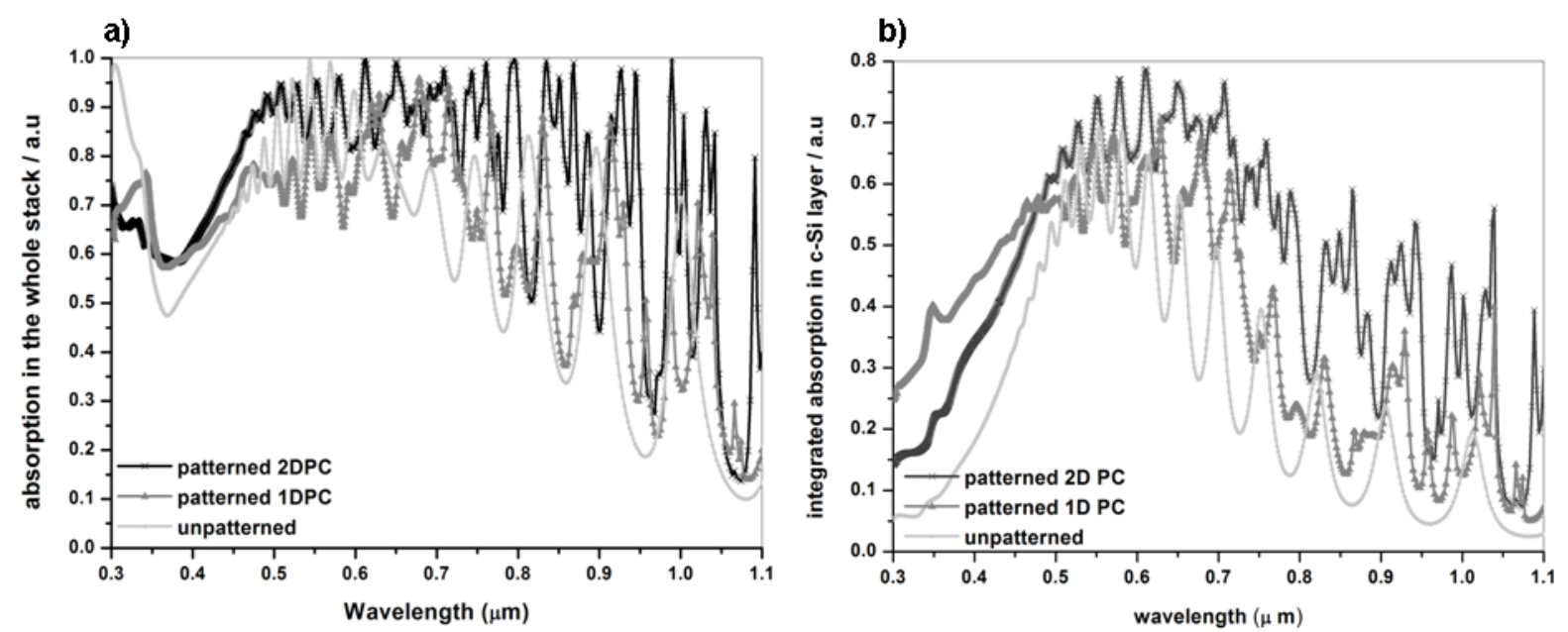

Fig.3. Absorption spectra in a) the whole stack and b) the c-Si layer for the 1D and 2D PC patterned stacks (L, $\mathrm{D} / \mathrm{L}$ and etching depth set to $610 \mathrm{~nm}, 35 \%$ and $140 \mathrm{~nm}$ respectively) compared to the unpatterned stack

When the wavelength is lower than the period, the absorption spectral mainly depends on the Fabry-Perot resonance thanks to the high index of membrane, therefore, which can be seen both the unpatterned and patterned cells. Over $610 \mathrm{~nm}$, multiple absorption peaks, which exist both for 1D and 2D PCs, are related to the PCs Bloch modes.

\section{Implementation the PC patterns in the fabrication cells}

In this section, we discuss on the steps leading to the patterning of our cells, using holographic lithography and RIE as well as ICP techniques. A more detailed description of those techniques will be developed in the following part. In particular, we will introduce the main techniques involved in this process. These can be tuned in order to reach the targeted parameters of the 1D and 2D PC (its period L, ff and its etching depth) and to transfer the obtained pattern in the different layers, while keeping the roughness of the etched sidewalls as low as possible.

Holographic lithography consists in irradiating a photosensitive resist using an interference pattern ${ }^{[17]}$. The sample, covered with a UV sensitive resist, is placed on a sample holder, associated to a mirror placed at $90^{\circ}$ of the sample. This system is illuminated by a laser beam; this generates fringes which irradiate the resist, with an inter-fringe distance $\mathrm{L}$ directly related to the angle $\theta$ through the relation $\mathrm{L}=\lambda_{\text {laser }} /(2 \sin \theta)$. In order to generate a 
2D pattern with a square symmetry at the surface of the sample, the irradiation needs to be repeated after rotating the sample by $90^{\circ}$. The resist is then exposed as schematically shown in Fig.4.a.

a)

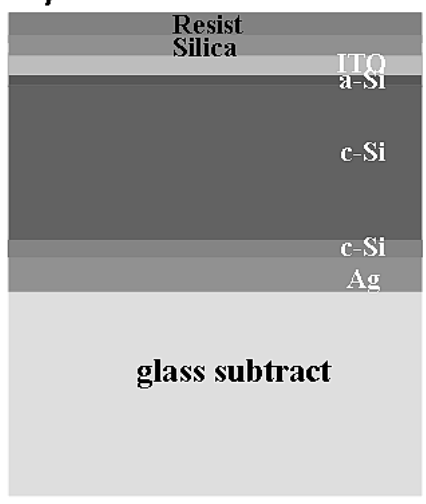

d)

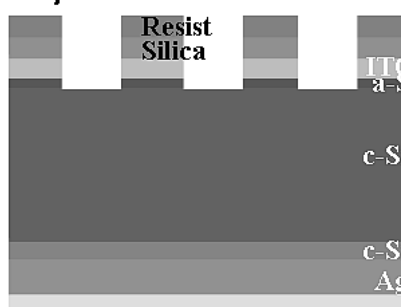

glass subtract b)

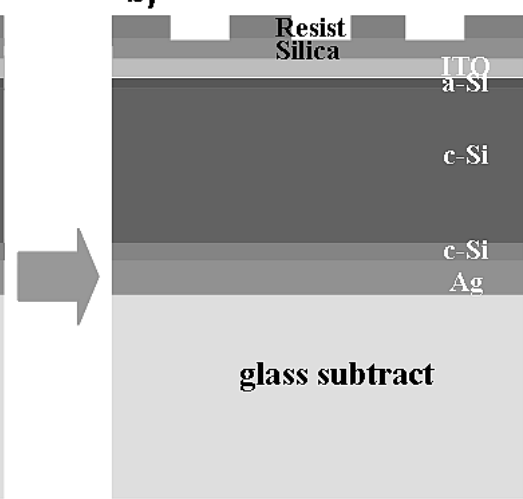

e)

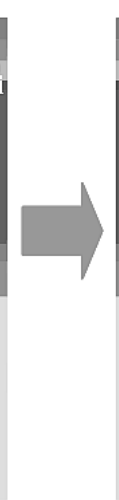

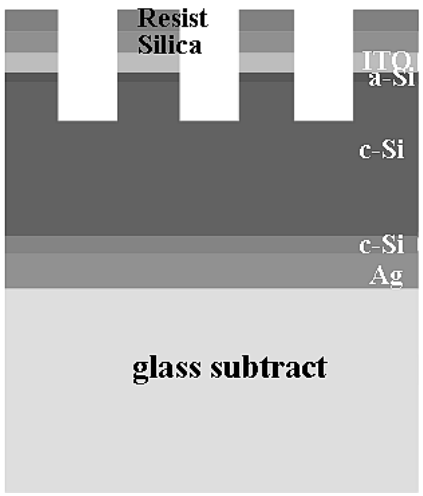

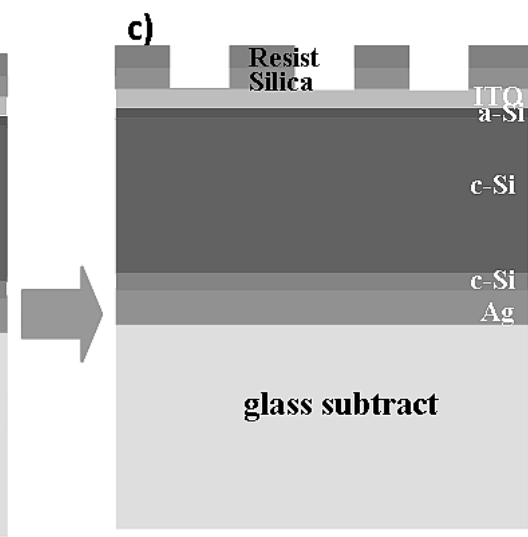

f)

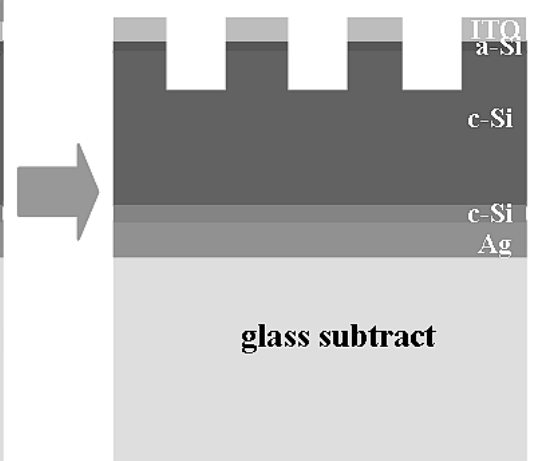

Fig.4. Main steps of the processes enabling to pattern the active layer as a 1D and 2D PC through holographic lithography (a, b), RIE(c, d, f) and ICP (e)

We implemented this generic process using a laser source at $266 \mathrm{~nm}$ with a power around $8 \mathrm{~mW}$ and a NEB 22 negative tone Chemically Amplified Resist (CAR). While the selected wavelength enables the patterning of structures with lattice parameters around $600 \mathrm{~nm}$, using negative resist is well-suited to the generation of holes in the resist, as in the case of our design. With this system, the processing sequence associated to holographic lithography includes sample cleaning and preparation, hexamethyldisilizane (HMDS) adhesion promoter spinning; the resist and HMDS are spun at $3000 \mathrm{rpm}$ for $30 \mathrm{~s}$. The post-apply bake (PAB) is performed at a temperature of $110^{\circ} \mathrm{C}$, followed by UV exposure, for $120 \mathrm{~s}$, and post-exposure bake (PEB), at $92^{\circ} \mathrm{C}$ for $180 \mathrm{~s}$. The development is performed in MF702 solution (supplied by Shipley Co.) for 20s; see Fig.4 b). The next step is a descum step in oxygen plasma for $8 \mathrm{~s}^{[19]}$. The PC pattern defined by holographic lithography is first transferred into a $100 \mathrm{~nm}$ thick $\mathrm{SiO}_{2}$ hard mask (as shown in Fig.4 c)), and then into the underlying ITO and a-Si layers, using RIE processes. Transfer into the $\mathrm{SiO}_{2}$ hard mask is achieved using a $\mathrm{CHF}_{3}$ plasma. The ITO layer was then etched by $\mathrm{CH}_{4}: \mathrm{H}_{2}$ plasma, and the a-Si:H layer was etched with a $\mathrm{SF}_{6}$ :Ar by RIE (as Fig.4 d)). In order to obtain vertical etched sidewalls, ICP is used to transfer the pattern in the c-Si layer using ICP with a high etch rates by high ion density and high radical density, which is displayed on Fig.4 e); finally, the resist and mask are removed by RIE (shown in Fig.4f)).

In our first test, another process is considered based on the following stack: glass $/ \mathrm{Al}(1 \mu \mathrm{m}) / \mathrm{c}-\mathrm{Si}(1 \mu \mathrm{m}) / \mathrm{SiO}_{2}$ $(0.1 \mu \mathrm{m})$. This stack, which is derived from the design presented above, is based on the established epi-free technology. It should be noted that the actual thicknesses of these layers may be slightly different due to technological uncertainties. A $100 \mathrm{~nm}$ thick silica layer was added on the top of the stack and acts as a hard mask during the etching of the c-Si layer. Starting from such samples, it is possible to first pattern the hard mask as a 1D or 2D PC (with a square symmetry) via holographic lithography, and then to transfer this pattern into the 
mask layer with RIE with a $16 \mathrm{sccm}$ flow, at $15 \mathrm{mT}$, and with a power of $100 \mathrm{~W}$ for $900 \mathrm{~s}$. The c-Si layer is finally etched by ICP using $50 \mathrm{sccm}$ for $\mathrm{Cl}_{2}$, radio frequency RF1 and RF2 with $500 \mathrm{~W}$ and $100 \mathrm{~W}$ for $45 \mathrm{~s}$ though the $\mathrm{SiO}_{2}$ mask to get vertical sidewalls, as shown on the SEM profile views, Fig.5 b) and d). Then the resist and $\mathrm{SiO}_{2}$ are removed at the end of etching process by RIE, which is shown in the front view Fig.5 a) and c). The lines and holes with a reasonable regularity and roughness could be transferred. The achieved period of $1 \mathrm{D}$ and 2D stacks are in the targeted range $550-650 \mathrm{~nm}$; the ff is just in the range corresponding to the optimum configuration (40\%-65\%), and etching depth is in the $100-140 \mathrm{~nm}$ range. The following steps are the deposition of the a-Si and ITO layers on the top of these patterned stacks.
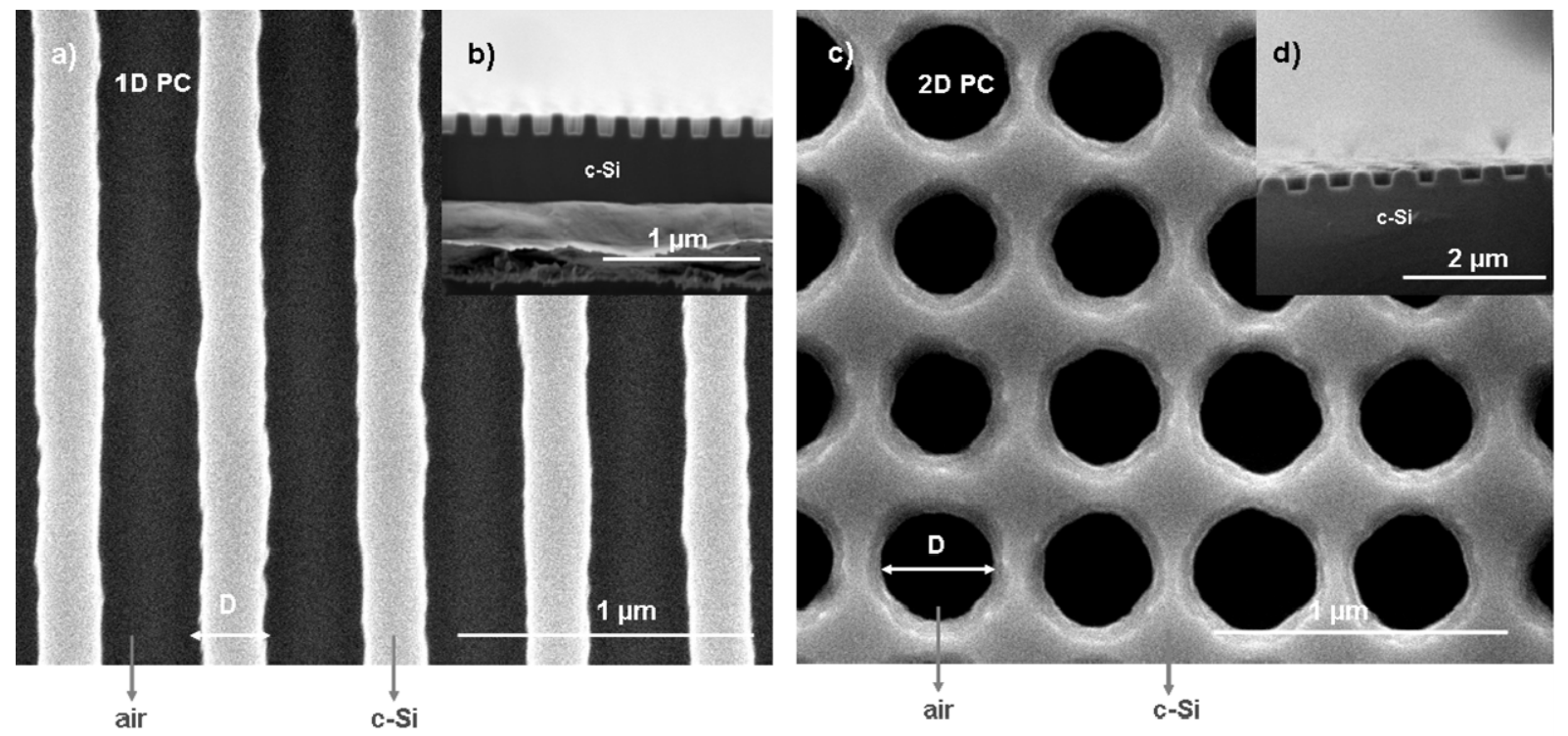

Fig.5. Top (a, c) and profile (b, d) view of a c-Si layer patterned as a $1 \mathrm{D}$ network (period around $\approx 550 \mathrm{~nm}, \mathrm{D} \approx$ $280 \mathrm{~nm}$ ) and a $2 \mathrm{D}$ network of round holes (period $\approx 550 \mathrm{~nm}, \mathrm{D} \approx$ around $350 \mathrm{~nm}$ ) into a $250 \mathrm{~nm}$ depth

\section{Conclusion and further work}

Further work will consist in the measurement of the optical properties of these 1D and 2D completed structures. It is noticeable that similar PC structures have already experimentally exhibited an improved absorption in $1 \mu \mathrm{m}$ thick c-Si layers. Finally, opto-electrical measurements are planned on complete PC structured solar cell samples, to determine their yield and to compare them to the one of non structured samples. Provided efficient electrical passivation, the yield improvement is expected to be close to the optical absorption improvement.

\section{Acknowledgements}

PC patterning was performed at the NanoLyon Technology Platform. Regis Orobtchouk is acknowledged for his support on laser holography. X.Meng acknowledges the China Scholarship Council (CSC).

\section{References}

[1] Y.Park, E.Drouard, O.El.Daif, X.Letartre, P.Viktorovitch, A.Fave, M.Lemiti, and C.Seassal, “Absorption enhancement using photonic crystals for silicon thin film solar cells", Opt. Expr. 17, 14312-14321 (2009).

[2] O. El Daif, E. Drouard, A. Fave, A. Kaminski, M. Lemiti, X. Letartre, P. Viktorovitch, C. Seassal, Proc. "Photonic Crystal Enhanced Absorption of Amorphous Silicon for Solar Cells", 24th European Photovoltaic Solar Energy Conference 548 (2009)

[3] O. El Daif, E Drouard, G. Gomard, A. Kaminski, A. Fave, M Lemiti, S. Ahn, S. Kim, P. Roca i 
Cabarrocas, H Jeon, C. Seassal, "Absorbing one-dimensional planar photonic crystal for amorphous silicon solar cell”, Opt. Expr. 18:A293 (2010)

[4] L.Zeng, P.Bermel, Y.Yi, B.A.Alamariu, K.A.Broderick, J.Liu, C.Hong, X.Duan, J.Joannopoulos, and L.C.Kimerlingv, "Demonstration of enhanced absorption in thin film Si solar cells with textured photonic crystal back reflector", Appl. Phys. Lett. 93, 221105 (2008).

[5] A.Bielawny, C.Rockstuhl, F.Lederer, and R. B.Wehrspohn, "Intermediate reflectors for enhanced top cell performance in photovoltaic thin-film tandem cells", Opt. Expr. 17(10), 8439-8446 (2009).

[6] V. Depauw , I. Gordon, G. Beaucarne, J. Poortmans R. Mertens, JP. Celis, "Large-area monocrystalline silicon thin films by annealing of macroporous arrays: Understanding and tackling defects in the material", J. Appl. Phys.106: 033516 1-033516 10 (2009)

[7] R. H. Franken, R. L. Stolk, H. Li, C. H. M. van der Werf, J. K. Rath, and R. E. I. Schropp, "Understanding light trapping by light scattering textured back electrodes in thin film n-i-p-type silicon solar cells", J. Appl. Phys.102(1), 014503 (2007).

[8] J. Müller, B. Rech, J. Springer, and M. Vanecek, "TCO and light trapping in silicon thin film solar cells", Sol. Energy 77(6), 917-930 (2004).

[9] A. Goetzberger and J.C. Goldschmidt and M. Peters and P. Löper, "Light trapping, a new approach to spectrum splitting", Sol. En. Mat. Sol. Cells 92, 1570-1578 (2008).

[10] L.Ferrier, O.El Daif, X.Letartre, P.Rojo Romeo, C.Seassal, R.Mazurczyk, and P.Viktorovitch, "Surface emitting microlaser based on 2D photonic crystal rod lattices", Opt. Expr. 17, 9780-9788 (2009).

[11] G. Gomard, E. Drouard, X. Letartre, X. Meng, A. Kaminski, A. Fave, M. Lemiti, E. Garcia-Caurel, C. Seassal, "Two-dimensional photonic crystal for absorption enhancement in hydrogenated amorphous silicon thin film solar cells", J. Appl. Phys. 108:123102 (2010)

[12] J. Y. Chen and K. W. Sun, "Enhancement of the light conversion efficiency of silicon solar cells by using nanoimprint anti-reflection layer", Sol. En. Mat. Sol. Cells 94, 629-633 (2010).

[13] M. Campbell, D.N. Sharp, M.T. Harrison, R.G. Denning, A.J. "Turberfield, Fabrication of photonic crystals for the visible spectrum by holographic lithography", Nature 404, 53-56 (2000).

[14] Cho, C.-O, Roh, Y.-G., Park, Y., Jeon, H. Lee, B.-S., Kim, H.-W., and Choe, Y.-H., "Photonic Crystal Slab Waveguides Fabricated by the Combination of Holography and Photolithography", Jpn. J. Appl. Phys 43, 1384-1387 (2004).

[15] Kim, D.-H., Cho, C.-O, Roh, Y.-G. Jeon, H., Park, Y. S., Cho, J., Im, J. S., Sone, C., Park, Y., Choi, W. J. and Park, Q-H., "Enhanced light extraction from GaN-based light-emitting diodes with holographically generated two-dimensional photonic crystal patterns", Appl. Phys. Lett. 87, 203508 (2005).

[16] W.Bogaerts, P. Dumon, D.Taillaert, V. Wiaux, S.Beckx, B. Luyssaert, J. Van Campenhout, D. Van Thourhout and R. Baets, "SOI nanophotonic waveguide structures fabricated with deep UV lithography", Photonics and Nanostructures 2, 81-86 (2004).

[17] X Meng, G. Gomard, O. El Daif, E. Drouard, R. Orobtchouk, A. Kaminski, A. Fave, M. Lemiti, A. Abramov, P. R. i Cabarrocas and C. Seassal, "Absorbing photonic crystals for silicon thin-film solar cells: Design, fabrication and experimental investigation”, Sol. En. Mat. Sol. Cells 95 32-38 (2011).

[18] R. Dewan and D. Knipp, "Light-trapping in thin-film silicon solar cells with integrated diffraction grating", J. Appl. Phys. 106(7), 074901 (2009).

[19] "Field Guide to Optical Lithography", Chris A. Mack, SPIE Press Book, 2006. 